\title{
Editorial
}

\section{AYUSH Systems of Medicine, a Viable Solution for COVID-19 amidst the Uncertainty of Vaccination \& Herd Immunity - an Indian Perspective}

\author{
Hima Bindu Ponnam ${ }^{1 *}$ and Butchi Raju Akondi ${ }^{2}$ \\ 'Homoeopathic Clinical Research Unit, Central Council for Research in Homoeopathy, Under Ministry of \\ AYUSH, Government of India, Hyderabad, Telangana, India; drdewdrop@gmail.com \\ 2Department of Clinical Pharmacy and Pharmacology, Ibn Sina National College for Medical Studies, \\ Jeddah, Saudi Arabia; drraju2020@gmail.com
}

In this era of major modern medical advancements, a way of lurking uncertainty still persists about human life in combating the upcoming novel viral diseases as present SARS-CoV2 virus causing COVID-19. COVID19 tremendously pushed the whole world into a wave of anxiety and stress in terms of uncertainty about life and death. As on $17^{\text {th }}$ May 2020, in India, the infected cases are 90,927 amongst which active cases 53,946, deaths are 2872 , and cured discharged cases are $34,108^{1}$. The Case fatality rate ${ }^{2}$ as on this date is around $3.2 \%$ in India and the recovery rate is $37.5 \%$ which seems to be very positive when compared with other suffering countries of the world. A precise introspection in this regard is very much essential at this juncture of endangered human life. Before analyzing the fact, lets us see why such an immense uncertainty prevailing regarding the treatment of COVID-19 and its containment. The last 2-3 months of fact sheet enabled us to understand that $81 \%$ of cases of COVID-19 were asymptomatic, $14 \%$ severely exhibited with symptoms and only $5 \%$ needed critical care ${ }^{2}$. At this stage where no known established treatment regimen is prevailing, the management of COVID-19 remains a challenge to the whole world. The treatment approach presently being utilized world-wide is the allopathic system of medicine with different opinions from experts including retroviral medicines (lopinavir \& retinovir combination used in HIV cases \& remsedivir developed for Ebola), Hydroxy-chloroquine (HCQ). These broad- spectrum antibiotic regimens being used currently are meant for treating bacterial infections coming after a virus attack but not to treat COVID-19 directly and they pose a lot many adverse side effects as on record ${ }^{3}$. In critical cases, oxygen therapy, intravenous fluid infusion, and life-saving ventilator therapy are being utilized in combination as per the condition of the patient.

Leaving aside the treatment options, let us evaluate the other possible strategies for the containment of the virus. The most awaited and the discussed option is the Vaccination which is under different phases of trials in different countries at present. Vaccination is the administration of a vaccine to help the immune system develop protection from a disease and it contains a microorganism or virus in a weakened, live or killed state, or protein or toxins from the organism. When we go through the history of vaccinations, it is evident that preparing a vaccine for an epidemic is a lengthy and expensive process, which may take about a year or two or even more ${ }^{4}$. Also how far the vaccination would succeed is doubtful on account of different strains of the virus and also a study by Li and her collaborators recently found it evident that the SARS-CoV2 virus has acquired mutations capable of substantially changing its pathogenicity and also its mutations again throwing us into uncertainty ${ }^{5}$.

Coming to the Herd Immunity (HI), a much-out spoken concept by many expert epidemiologists. Herd Immunity happens when so many people in a community

*Author for correspondence 
become immune to an infectious disease that it stops the disease from spreading. It happens in two ways: one is that many people contract the disease and in time build up an immune response to it (natural immunity) and the other many people are vaccinated against the disease to achieve immunity. As we already discussed the option of vaccination which have a higher chance of failure. Coming to the natural herd immunity, in which we are leaving the population at risk to contract the disease. Again this depends on the average number known as the basic reproductive number commonly symbolically designated as "R0" - that is the average number of other persons that an infectious person will infect with an agent in a completely susceptible population. This may become very risky when the clinical consequences of the infection are greater for the vulnerable low immunity groups (children, old age, and pregnant women) ${ }^{6}$. The United Kingdom initially opted for it but in view of the fatal consequences of increasing mortality rates had to withdraw opting for lockdown restrictions in their country ${ }^{7}$. Ultimately, herd immunity option also exhibits a risk of mortality and uncertainty.

Finally comes the much-weighted statement about COVID-19 prevention is possessing a natural strong immunity within the human body. Moving into the introspection of the Indian perspective, India is a country full of rich ancient culture and heritage lasting from thousands of years. Many ancient scriptures envisaged the use of a vast number of natural remedies in boosting the immunity of a person. In India when we critically observe the treatment regimens opted for, it has been found that a considerable amount of people give preference to Ayurveda, Yoga, Unani, Siddha, Sow Rigpa, and Homoeopathy (AYUSH) systems of medicine which are the rich heritage of India. Even the Indian Government supports these systems of medicine under the National Health Mission and taken necessary steps to mainstream these systems of medicine to bring an equal status to the allopathic system of medicine. The Indian government has formed a separate Ministry of AYUSH in 2014 to strengthen the potential of these systems of medicine in reaching the masses. The Confederation of Indian Industry website states that the AYUSH is currently a $\$ 10$ billion market and is expected to grow to a $\$ 15$ billion market by 2020 (https://www.ciiblog.in/industry/ayushis-booming-in-india/).

According to AYUSH systems, the common reasons for preferring these treatment options includes lesser side effects, effective disease management, and improvement of quality of life and health promotion, higher preventive potential, and cost-effectiveness. ${ }^{8,9,10}$ All these systems are highly known for their holistic approach of treatment and their main modus operandi of remedies is to strengthen the natural immunity of the individual which in turn stimulates the human body to fight with the external infectious agent. The experts on AYUSH claim that the whole human population irrespective of the vulnerable/ non-vulnerable groups would benefit from fighting with the current COVID-19 crisis. These medicines operate in two ways - one is playing a prophylactic role in the unaffected individuals and on the other way effectively containing the intensity of the disease in the affected individuals ${ }^{3}$. Indian government for the containment of COVID-19 has issued an advisory of AYUSH medicines on $6^{\text {th }}$ March 2020 (PIB released in Jan 2020) which are being used by the population of India very widely, thus boosting their internal immune powers and protecting themselves from COVID-19 ${ }^{11}$.

As per the Ministry of AYUSH, Government of India advisory, the treatment modes with AYUSH medicines are classified as follows: i) Preventive and prophylactic, ii) Symptom management of COVID19 like illnesses, iii) Add on Interventions to the conventional care. As discussed above the preventive and prophylactic category of medicines act as immune boosters. For example: In Ayurveda system - the ancient medicine Samshamani Vati 500mg twice a day with warm water for 15 days (aqueous extract of Tinospora cordifolia $)^{12,13}$. Next in Siddha system of medicine Nilavembu kudineer ${ }^{14,15}$ decoction $60 \mathrm{ml}$ twice a day for 14 days (aqueous extract of Andrographis paniculata \& others). Coming to Unani system of medicine Preparation of decoction by boiling Behidana (Cydonia oblonga) ${ }^{16} 3 \mathrm{gm}$, Unnab (Zizyphus jujube) ${ }^{17} 5$ in number. Sapistan (Cordia myxa) $)^{9,18}$ in number in water. (Boil these in $250 \mathrm{ml}$ water- boil it till it remains half- filter it - keep in a glass bottle and use it lukewarm). The drugs used in the preparation of this decoction have been reported to have Antioxidant activity, Immuno-modulatory, antiallergic, smooth muscle relaxant activity, and Antiinfluenza activity. This decoction may be taken twice a day for 14 days. Coming to the Homoeopathy system of medicine, Arsenicum album $30^{19}$, daily once 4 pills in an empty stomach for three days is recommended by the experts in that stream of medicine. The dose should be repeated after one month by following the same schedule 
till Coronavirus infections prevalent in the community. In fact, they even offer evidence for its effectiveness in the earlier epidemics like Spanish flu, Japanese encephalitis, chikungunya, etc. ${ }^{11}$. Lastly, AYUSH claims the practice of Yogasana and Pranayama under the guidance of qualified Yoga instructor is recommended during this pandemic ${ }^{20}$.

In the present situation of lockdown restrictions in India which cannot be continued for long periods due to the result of an economic catastrophe in the country, we need to accept the reality of living life along with the risk of SARS-CoV2 virus infection. Therefore:

"I envisage that the best viable solution in the current COVID-19 would be to adopt lifestyle modifications, using these age-old AYUSH medicines and make them a part of our daily life-enhancing our internal immune powers to fight the disease effectively.

\section{References}

1. Government of India [Internet]. https://www.mygov.in/ covid-19/. 2020 [cited 17 May 2020]. Available from: https://www.mygov.in/covid-19/

2. Spychalski P, Błażyńska-Spychalska A, Kobiela J. Estimating case fatality rates of COVID-19. The Lancet Infectious Diseases. 2020; 20:30246-2.

3. Ali I, Alharbi O. COVID-19: Disease, management, treatment, and social impact. Science of the Total Environment. 2020; 728:138861.

4. Lurie N, Saville M, Hatchett R, Halton J. Developing Covid19 Vaccines at Pandemic Speed. New England Journal of Medicine. 2020; 382(21):1969-1973.

5. Coronavirus's ability to mutate has been vastly underestimated, and mutations affect deadliness of strains, Chinese study finds [Internet]. https://www.scmp.com. 2020 [cited 17 May 2020]. Available from: https://www.scmp. com/news/china/science/article/3080771/coronavirusmutations-affect- deadliness-strains-Chinese-study

6. Smith P. Concepts of herd protection and immunity. Procedia in Vaccinology. 2010; 2(2):134-139.

7. Science media center [Internet]. https://www.sciencemediacentre. org. 2020 [cited 17 May 2020]. Available from: https://www. sciencemediacentre.org/expert-comments-about-herdimmunity/

8. Boovaragasamy C, Narayanan S. Utilization of AYUSH in public health care system: a review. Int J Community Med Public Health. 2019 Jun; 6(6):2730-32.

9. Shankar D, Patwardhan B. AYUSH for New India: Vision and Strategy. Editorial/Journal of Ayurveda and Integrative Medicine. 2017; 8:1.
10. Dora BB, Gupta S, Sital S, Singh M. Importance of AYUSH in present health care perspective. Research and Reviews: Journal of Medical Science and Technology (RRJoMST). 2015; 4(3)5-8.

11. The AYUSH [Internet]. https://www.ayush.gov.in. 2020 [cited 17 May 2020]. Available from: https://www.ayush. gov.in/docs/125.pdf [accessed on $17^{\text {th }}$ May 2020).

12. Kalikar MV, Thawani VR, Varadpande UK, Sontakke SD, Singh RP, Khiyani RK. Immunomodulatory effect of Tinospora cordifolia extract in human immuno-deficiency virus positive patients. Indian J Pharmacol 2008; 40 (3):107-10.

13. More P., Pai K. Immunomodulatory effects of Tinospora cordifolia (Guduchi) on macrophage activation. Biol. Med. 2011; 3: 134-140.

14. Christian GJ, Subramanian M, Periyasami D, Manickavasakam K, Gunasekaran P, Sivasubramanian S et al., Protective Effect of Poly Herbal Siddha Formulation -Nilavembu Kudineer against common Viral Fevers Including Dengue - A case Control Approach. Int J Pharm Sci Res 2015; 6(4):1656-60.

15. Kalai arasi R, Jeeva Gladys R, Elangova S, Soundararajan DK, Mubarak H. Kanakarajan A. Combination of Nilavembu Kuidineer and Adathodai Manapagu in the Management of Dengue Fever. International Journal of Current Research 2013; 5(4):978-981.

16. Al-Snafi A. The medical importance of Cydonia oblonga A review. Journal of Pharmacy 2016; 6(2):87-99.

17. Chi A, Kang C, Zhang Y, Tang L, Guo H, Li H, Zhang K. Immunomodulating and antioxidant effects of polysaccharide conjugates from the fruits of Ziziphus Jujube on Chronic Fatigue Syndrome rats. Carbohydr Polym 2015; 122:189-96.

18. Ali WR, Al-AsadyZT and Ibrahim AA. Immunomodulatory of Cordia myxa (L.) aqueous extract fruit in immunized mice with hydatid cyst fluid. Journal of Natural Science Research 2015; 5(10): 75-83.

19. Chakraborty P, Lamba CD, Nayak D, John MD, Sarkar DB, Poddar A, Arya J, Raju K, Vivekanand K, Singh HB, Baig H, Prusty AK, Singh V, Nayak C. Effect of individualized homoeopathic treatment in influenza like illness: A multicenter, single blind, randomized, placebo controlled study. Indian J Res Homoeopathy 2013; 7:22-30.

20. Morgan N, Irwin MR, Chung M, Wang C. The Effects of Mind-Body Therapies on the Immune System: MetaAnalysis. PLoS ONE 2014; 9(7): e100903. 